\title{
Credible Sales Mechanisms and Intermediaries
}

\author{
David McAdams and Michael Schwarz *
}

\begin{abstract}
In this paper, we consider a seller who faces several buyers and lacks access to an institution to credibly close a sale. If buyers anticipate that the seller may negotiate further, they will prefer to wait before making their best and final offers. This in turn induces the seller to bargain at length with buyers, even if doing so is costly. When the seller's cost of soliciting another round of offers is either very large or very small, the seller credibly commits to an auction and experiences negligible bargaining costs. Otherwise, there may be several rounds of increasing offers and significant seller losses. In these situations, an intermediary with a sufficiently valuable reputation and/or weak marginal incentives regarding price can create value by credibly committing to help sell the object without delay.
\end{abstract}

*David McAdams at MIT Sloan School of Management, mcadams@mit.edu. Michael Schwarz at UC Berkeley and NBER, mschwarz@berkeley.edu. We thank seminar audiences at Berkeley, Penn, UC Riverside, Stanford, USC for helpful comments. 


\section{Introduction}

The auction paradigm has dominated the academic analysis of real-world sales mechanisms, despite the fact that buyers and sellers in many transactions conspicuously lack the ability to commit to an orderly sales process. In his paper "What Really Matters in Auction Design", Paul Klemperer (2002) emphasizes the importance of 'credibility of the rules', in particular rules for closing a sale: "Sealed-bid auctions [may be] vulnerable to rule-changing by the auctioneer. For example, excuses for not accepting a winning bid can often be found if losing bidders are willing to bid higher. The famous RJR-Nabisco sale went through several supposedly final sealed-bid auctions (Burrough and Helyar, 1990)." This paper is the first to attempt to formalize this insight.

The recent high-profile sale of the General Motors Building in Manhattan for $\$ 1.4$ billion highlights sellers' inability to commit to rules ${ }^{1}$ The owners of this building announced that they would sell it using a first-price auction. According to the New York Times, this auction "drew the highest bids ever for a skyscraper in the United States". After the bidding, however, the owners violated the announced rules by allowing one of the buyers to make a late offer with knowledge of others' offers.

Corporate acquisitions provide another important class of examples where sellers can not commit to a sealed-bid auction. The board of directors of any target firm must disclose all bids to shareholders and consider any subsequent offers, or else be vulnerable to shareholder lawsuits. How can an acquisition target get buyers to make good offers when there can always be another round? One possible solution is the use of break-up fees. For example,

\footnotetext{
${ }^{1}$ Solow Building Corporation vs 767 Fifth Avenue LLC, et al (Delaware Court of Chancery, CA\#20542, 2003). See "Lawsuit Seeks to Block Sale of G.M. Building" by Charles Bagli, New York Times, September 20, 2003. We thank Robert Gertner for sharing this example.
} 
cardiovascular device-maker Guidant accepted a $\$ 24.6$ billion offer from Johnson \& Johnson that included a $\$ 705$ million break-up fee. Shortly thereafter, Boston Scientific offered $\$ 2.7$ billion more. Guidant accepted Boston Scientific's offer but had to pay J \& J $\$ 705$ million $2^{2}$ A break-up fee may help induce buyers to make serious offers, but also may lead to inefficiencies. (The highest-value buyer may not win if the break-up fee is larger than the difference between his and the second-highest value.)

More generally, a seller who can not commit to close a sale may benefit from making it more costly for herself to add another round to negotiations. In this paper, we consider such a seller. If buyers anticipate that the seller may solicit another round of offers, they will be reluctant to make serious offers and the seller may experience costly delay. To induce buyers to make serious offers, the seller must be able somehow to credibly commit to leave money on the table, i.e. to stop negotiating even when (in equilibrium) she could have gotten a higher price by negotiating further.

How much money the seller can commit to leave on the table in our model depends on two factors. First, can the seller tie this commitment to a valuable reputation? As one would expect, the seller experiences less delay when she stands to lose a more valuable reputation by haggling with buyers. Second, is it costly for the seller to solicit an additional round of offers? (We refer to such costs as 'per-round delay costs' $4^{3}$ The seller experiences the least total delay costs when per-round delay costs are either very small or very large.

Per-round delay costs become very large when a deadline approaches, at which time the seller can credibly commit to a first-price auction. For instance, a well-publicized pro-

\footnotetext{
${ }^{2}$ See "Rival suitor raises stakes for Guidant: Boston Scientific trumps Johnson \& Johnson offer" by Mark Jewell, Associated Press, January 18, 2006.

${ }^{3}$ Delay costs are similar to but not the same as break-up fees. Both may deter a seller from negotiating further with buyers, but neither is a special case of the other.
} 
curement negotiation between Spanish airline Iberia and airplane manufacturers Boeing and Airbus dragged on for months $4^{4}$ Finally, Iberia CFO Enrique Dupuy de Lome called a special board meeting and promised to announce the winner. He prepared separate Powerpoint presentations announcing a deal with each supplier, and waited. Just hours before the meeting, Airbus and Boeing presented new offers at significantly lower prices. With no time to bargain further, Mr. Dupuy compared the offers, chose Airbus, and closed the deal.

When per-round costs are very small, the seller can credibly commit to an ascending price auction and experience negligible delay. Sotheby's art auctions seem to fall into this category. The opportunity cost associated with spending a few more seconds auctioning any particular item is small, and sales are completed rapidly.

When per-round costs are substantial but not very large, finally, there will typically be a few rounds of increasing offers and significant seller losses due to delay. (Numerical examples show that such losses can easily be more than $10 \%$ of the total gains from trade.)

When a seller might otherwise experience significant losses due to buyers' strategic delay, we would expect intermediaries to help the seller conduct the sale. To see the effects of intermediaries on bidding, consider the way that real estate agents change the dynamics of home sales $5^{5}$ A typical real estate commission is only about $3 \%$ for the seller's agent, of which a portion is paid to his office. With such low-powered incentives to increase the price, the seller's agent may resist the temptation to solicit additional round of offers. Counterintuitively, this may actually help the seller relative to the alternative of selling her home

\footnotetext{
${ }^{4}$ See "Airbus and Boeing duke it out to win lucrative Iberia deal" by Daniel Michaels, Wall Street Journal, March 10, 2003.

${ }^{5}$ Real-estate agents provide a variety of other valuable services, in addition to encouraging buyers to make serious offers quickly. In particular, by listing and marketing the property, a real estate agent may attract more buyers than the seller could on her own.
} 
without an agent $5^{6}$ Buyers know that the seller is likely to accept the best current offer, so they make their best offers immediately. If the seller had listed the property without using an agent, buyers would know that the seller has a strong incentive to renegotiate and so would be hesitant to make serious offers.

Intermediaries are ubiquitous in markets ranging from corporate acquisitions to collectible art. The share of asset value captured by such intermediaries ranges from about $1 \%$ in the market for acquisition $7^{7}$ to about $6 \%$ for real estate transactions and routinely exceeds $20 \%$ in the art world. An obvious and important source of value creation by intermediaries stems from their marketing and negotiation skills as well as their ability to verify quality and create a marketplace 8 This paper argues that intermediaries may also create value by their ability to credibly commit to a sales mechanism.

Our work complements the existing literature on auction theory and mechanism design. Relative to the benchmark performance of a standard efficient auction, 9 this literature shows how much extra expected revenue a seller can raise given complete commitment power. See e.g. Bulow and Klemperer (1996). Our work shows how a seller who lacks the power to credibly close a sale may achieve significantly less than this benchmark.

The most closely related literature is that on 'mechanism design without commitment'. See e.g. McAfee and Vincent (1997), Skreta (2004), and Vartiainen (2003). These papers

\footnotetext{
${ }^{6} \mathrm{~A}$ seller can do even better by soliciting another round of offers when buyers do not expect her to do so. This is consistent with the findings of Levitt and Syverson (2005), who showed that real estate agents hold out for more offers when selling their own homes, and succeed in getting higher average prices.

7 McLaughlin (1990) reports average investment banking fees of $1.29 \%$.

8 See Ellison, Fudenberg, and Mobius (2004) on network effects associated with creating a marketplace.

${ }^{9} \mathrm{~A}$ standard efficient auction is one in which the buyer with the highest value wins, and any buyer who never wins pays nothing, e.g. an English auction or (in a symmetric setting) a first-price auction with zero reserve price. By the Revenue Equivalence Theorem, all such auctions generate the same expected revenue.
} 
consider a seller who has the power to commit to a mechanism for the present round but not to commit ahead of time to a mechanism for future rounds, in case the object is not sold today. Our paper complements this literature by considering additional issues that arise when delay is costly and the seller is unable to commit to a mechanism for the present round either.

There is a vast literature on bargaining with private information in the context of a single seller and a single buyer 10 In such settings, typically, the seller is worse off and the buyer is better off when the seller lacks the power to commit. See e.g. Bulow (1982). This is also true in our setting when the seller faces a single buyer. Once the seller faces several buyers in our model, however, the seller is worse off but buyers are no better off when the seller lacks commitment power. Ultimately, bidding competition among the buyers constrains buyer profits in our model, not the seller's ability (or lack thereof) to commit to close the sale.

The rest of the paper is organized as follows. Section 2 presents the model, describes a perfect Bayesian equilibrium, and explores properties of this equilibrium. Section 3 then discusses ways that an intermediary can profitably change the game. Section 4 provides concluding remarks. Formal proofs of most results are relegated to the Appendix.

\section{Bargaining without an intermediary}

To what extent can a seller induce buyers to make serious offers, when there may always be another round? We consider this issue in a specific, relatively tractable setting. A seller of a single object faces several buyers. The seller has zero value for the object while the buyers have i.i.d. private values. (All agents are risk neutral.) Each buyer makes an offer each round. The seller may accept a current offer or request a new round of offers. Because the

\footnotetext{
${ }^{10}$ See Ausubel, Cramton, and Deneckere (2002) for a survey.
} 
seller has this flexibility, buyers are hesitant to make serious offers and multiple rounds of offers typically precede any sale. This can create delay costs for the seller.

To highlight what we feel is most novel in our analysis while keeping it tractable, we consider a seller with very little bargaining power. (i) The seller finds delay costly, while buyers do not. (ii) The seller's value is known, but buyers' values are private. (iii) Only buyers can make offers. By contrast, the seller is only endowed with the power to accept an offer made by a buyer or ask for more offers.

Given a single buyer, our model becomes a special case of Rubenstein bargaining where only the buyer makes offers, agreement is immediate, and the buyer gets all of the surplus. However, we consider the case of multiple buyers. In this setting, the seller's ability to extract surplus hinges on her ability to induce buyers to compete against each other.

\subsection{Model}

The (female) seller has a single object and faces $N \geq 2$ (male) buyers in the following multi-round game.

Bargaining Game. Figure 1 describes the basic timing of each round $T=0,1,2, \ldots$.

\begin{tabular}{c|c|c} 
Buyers make & 'Going, going, & Object sold or proceed \\
offers & gone?' & to next round \\
\hline
\end{tabular}

Figure 1: Timing of the Bargaining Game, round $T \geq 0$.

Buyers make offers. Each buyer simultaneously makes an offer. All buyer offers are pub- 
$\operatorname{lic} 1112$

'Going, going, gone?' Each buyer then has the simultaneous opportunity to indicate through a cheap talk announcement whether he wants the game to 'end' or 'continue'.

Object sold or proceed to next round. The seller chooses whether to sell the object immediately for a price equal to the highest current buyer offer ${ }^{13}$ or does not sell the object and the game proceeds to the next round. In the latter case, the seller designates which buyers will be 'active' (i.e. allowed to make offers) in the next round. A buyer who is inactive in one round might become active in a later round.

Buyer values. Each buyer $i$ has a private value $v_{i}$ drawn i.i.d. from a known atomless distribution having support $[\underline{V}, \bar{V}]$ with $\underline{V} \geq 0$ and density $f(\cdot)$. Buyer $i$ 's surplus from winning with bid $b$ in round $T$ is $v_{i}-b$ and zero otherwise. Each buyer's objective is to maximize his expected surplus.

Seller delay cost. If the object is sold in round $T$, the seller's total delay cost is $C(T)$ with per-round delay cost $c(T) \equiv C(T+1)-C(T)$. We shall assume that $C(0)=0$ and $c(T) \geq 0$ for all $T \geq 0$. Buyers do not incur any delay cost.

Seller reputation. The seller is tempted to ask for another round of offers as long as she expects sufficiently higher offers (in equilibrium) so as to increase revenue net of delay cost. However, the seller enters the game with a reputation that has value $R \geq 0$, and loses that reputation if she 'nickel-and-dimes' buyers.14 More precisely, we will focus on perfect

\footnotetext{
${ }^{11}$ It is not crucial that offers are automatically made public. In a version of our model in which the seller has discretion regarding which offers to reveal, she chooses to reveal them all.

${ }^{12}$ In a world where buyers' offers can not be revealed, the seller can credibly commit to a first-price auction and hence avoid all delay costs.

${ }^{13}$ See the Appendix for details on the tie-breaking rule.

${ }^{14}$ In the Web Appendix, we consider a repeat seller for whom such a reputation emerges endogenously as
} 
Bayesian equilibria in which, on the equilibrium path, buyers expect that the seller will accept the highest current offer unless asking for another round will increase her expected net revenue by more than $R$. (Since buyer offers are public and the seller has no private information, every buyer is able to compute the seller's expected equilibrium profit after asking for another round of offers.) If the seller deviates and asks for another round of offers when buyers expect her not to do so, the seller loses her reputation and buyers henceforth expect the seller to ask for more offers as long as doing so will increase her expected net revenue.

Seller profit. If the object is sold in round $T$ at price $p$ and the seller does not lose her reputation, the seller's ex post profit is $p-C(T)$. If the object is sold in round $T$ at price $p$ and the seller loses her reputation, the seller's ex post profit is $p-C(T)-R$.

Discussion: 'Seller delay cost' in our model might be more accurately described as 'costs that the seller incurs when soliciting another round of offers'. Such costs could be directly

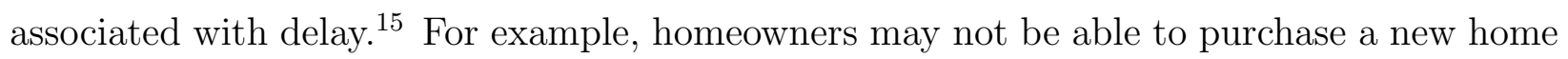
(or fully enjoy their current home) as long as it remains for sale. Firms also may prefer not to be known as being for sale, since this creates uncertainty for customers and other stakeholders that can not be resolved until after the sale is complete.

Of course, there may be other costs associated with soliciting more offers that have nothing to do with delay per se. For example, the opportunity cost of managerial attention part of a perfect Bayesian equilibrium of a repeated game.

${ }^{15}$ Delay between rounds of offers could be substantial if it takes time to communicate with buyers, for buyers to reflect before making new offers, and/or for the seller to reflect before accepting an offer. This could in turn be due to technological constraints, the need for managerial approval, etc. Another possible reason is that a seller may be unable to commit not to employ fake bids or shill bidders unless there is substantial delay between rounds. (Time may be needed for the buyers to verify that all bids are genuine.) 
associated with reviewing offers could be costly.

Throughout the text, we restrict attention to the special case in which buyers' values $v_{i}$ are i.i.d. uniform over an interval $[\underline{V}, \bar{V}]$. In this case, a perfect Bayesian equilibrium can be described in closed form. (The Appendix extends our equilibrium construction for general distributions.)

\subsection{One round of offers: first-price auction}

Can the seller credibly commit to a first-price auction, i.e. commit to sell the object after a single round of offers? The answer to this question depends crucially on the extent of per-round delay costs as well as the value of the seller's reputation.

'Deadlines'. Consider first the case in which the seller has no reputation to lose but there are real $\operatorname{costs} c(0)$ associated with soliciting a second round of offers. Time $T=0$ is a deadline for the seller when $c(0)>\bar{V}$, since the maximal possible benefit from soliciting a second round of offers is less than the cost of doing so. Indeed, the seller can credibly commit to a first-price auction as long as $c(0) \geq \frac{\bar{V}-V}{N} .16$ If delay costs are smaller than this, the seller can still commit to a first-price auction, but only if her at-risk reputation is sufficiently valuable that $c(0)+R \geq \frac{\bar{V}-\underline{V}}{N}$. The key to credibly committing to a first-price auction in either case is the ability to commit to leave enough 'money on the table'.

Suppose to the contrary that $c(0)+R<\frac{\bar{V}-\underline{V}}{N}$. In this case, first-price auction strategies

\footnotetext{
${ }^{16}$ If buyers bid as if in a first-price auction, we may infer from bid $b$ that a buyer has value $b+\frac{1}{N-1}(b-\underline{V})$. Let $b_{0}^{(1)}$ denote the highest time-0 buyer offer and $v^{(1)} \equiv b_{0}^{(1)}+\frac{1}{N-1}\left(b_{0}^{(1)}-\underline{V}\right)$ the inferred value of the buyer who made this offer. Note that buyers shade their time- 0 offers below their values by at most $\frac{\bar{V}-\underline{V}}{N}$. As long as $c(0) \geq \frac{\bar{V}-\underline{V}}{N}$, then, no buyer will possibly offer more than $b_{0}^{(1)}+c(0)$ at time 1 . Thus, the seller prefers to accept the highest time-0 offer. Anticipating this, buyers indeed bid as if in a first-price auction.
} 
can not be supported in perfect Bayesian equilibrium. Suppose otherwise. Since a bidder's bid in a first-price auction is strictly increasing in his value, buyers will be able to infer each others' true value for the object once these bids are revealed. For example, suppose that two or more buyers have value $\bar{V}$ and bid $\underline{V}+(\bar{V}-\underline{V}) \frac{N-1}{N}$. These buyers are willing to pay $\frac{\bar{V}-\underline{V}}{N}$ more for the object. By revealing their bids, the seller can induce them to offer $\bar{V}$ at time 1 , increasing revenue by more than $R+c(0)$. Anticipating this, buyers will not bid as in a first-price auction.

For the remainder of the paper, we describe and explore in depth a perfect Bayesian equilibrium in a setting encompassing both of these cases. See the Web Appendix for an extension that allows the seller to set an (endogenous implicit) reserve price ${ }^{17}$

\subsection{Multiple rounds of offers}

Preliminaries. For any given profile of values $\left(v_{1}, \ldots, v_{N}\right)$, recursively define

$$
\begin{aligned}
& \underline{v}_{T}\left(v_{1}, \ldots, v_{N}\right) \equiv \underline{V}+\sum_{T^{\prime}=0}^{T-1} M_{T^{\prime}}\left(v_{1}, \ldots, v_{N}\right)\left(R+c\left(T^{\prime}\right)\right) \\
& M_{T}\left(v_{1}, \ldots, v_{N}\right) \equiv \#\left\{i: v_{i} \geq \underline{v}_{T}\left(v_{1}, \ldots, v_{N}\right)\right\}
\end{aligned}
$$

where $M_{0} \equiv N$ and $\underline{v}_{0} \equiv \underline{V}$. To save space, we also use simpler notation $\underline{v}_{T}$ and $M_{T}$. $M_{T}$ will arise as the equilibrium number of active buyers at time $T$ while $\underline{v}_{T}$ will arise as the minimum value of all such buyers in equilibrium.

Note: $\underline{v}_{T}$ is non-decreasing in $T$ and $M_{T}$ is non-increasing in $T$.

\footnotetext{
${ }^{17}$ When the seller's reputation $R>0$, we describe multiple equilibria of our game. In the text, we focus on an equilibrium in which the seller does not set a reserve price. In the Web Appendix, we consider another equilibrium in which buyers are allowed to make any offers but the seller never sells the object for a price less than $r$, where $r \leq R$. (The seller can not credibly commit to a reserve price higher than $R$.)
} 
Theorem 1. A perfect Bayesian equilibrium exists such that the following occurs during round $T$ on the equilibrium path of play. (i) Buyer $i$ offers

$$
\begin{aligned}
b_{i, T} & \equiv s_{T} \equiv \underline{v}_{T}+\left(M_{T}-1\right)(R+c(T)) \text { if } v_{i} \geq \underline{v}_{T}+M_{T}(R+c(T)) \\
& \equiv \underline{v}_{T}+\left(v_{i}-\underline{v}_{T}\right) \frac{M_{T}-1}{M_{T}}<s_{T} \text { if } \underline{v}_{T} \leq v_{i} \leq \underline{v}_{T}+M_{T}(R+c(T)) \\
& \equiv v_{i} \text { if } v_{i} \leq \underline{v}_{T}
\end{aligned}
$$

(ii) Buyer $i$ says 'end' unless he offered $s_{T}$. (iii) The seller accepts the highest offer unless two or more buyers offered $s_{T}$. In that case, the game continues and the active buyers in round $T+1$ are those who offered $s_{T}$ in round $T$.

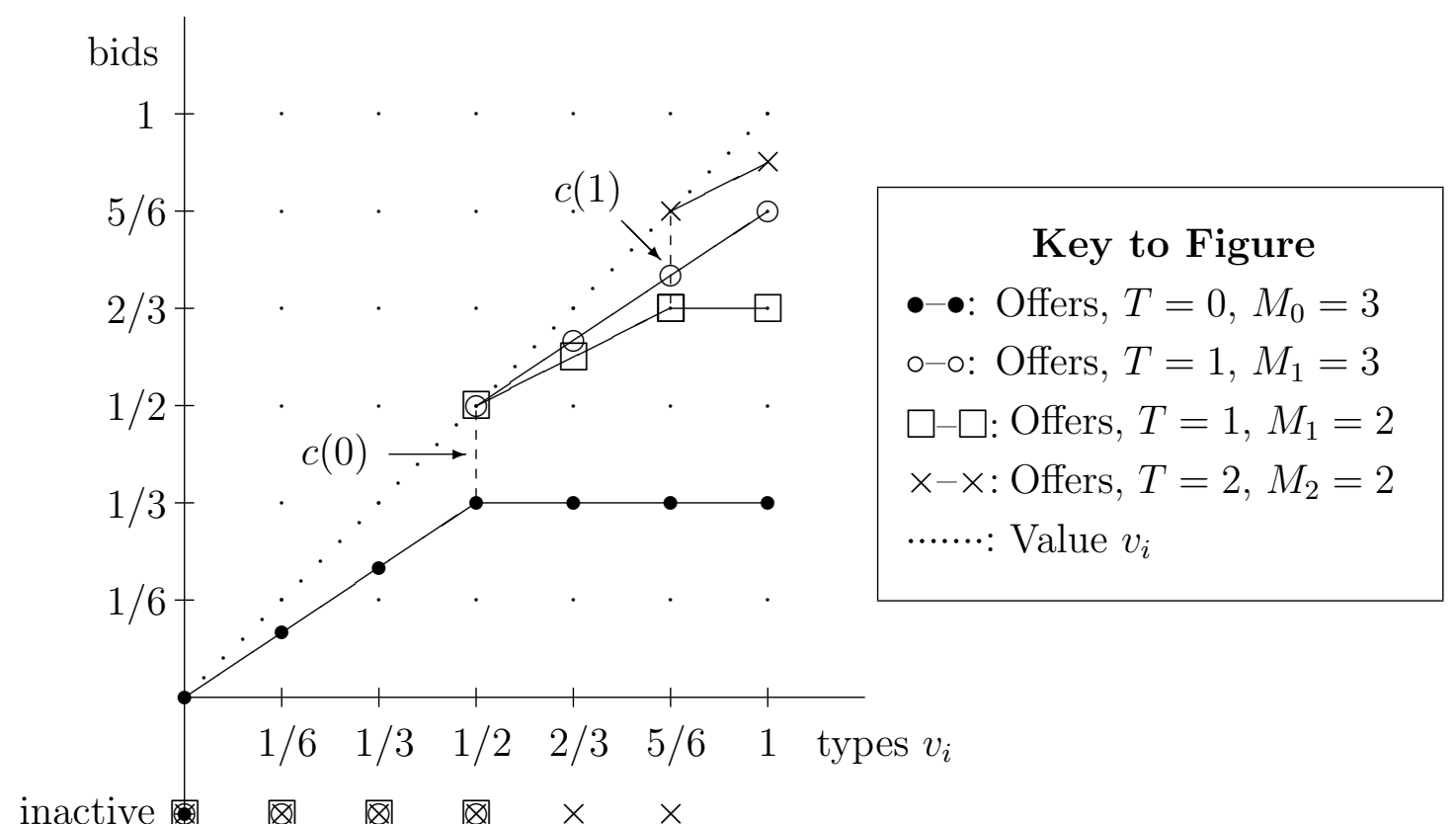

Figure 2: Equilibrium offers and activity given three buyers with i.i.d. values $v_{i} \sim U[0,1]$, no seller reputation, and delay $\operatorname{costs} c(T)=\frac{1}{6}$ for all $T$.

Example. Figure 2 illustrates the equilibrium path of play when $N=3,[\underline{V}, \bar{V}]=[0,1]$, $R=0, c(T)=0$ for all $T$. 
Time 0. Each buyer's offer corresponds to the line traced by filled dots. Any buyer with value $v_{i} \leq 1 / 2$ offers $2 v_{i} / 3$ and says 'end' while all others offer $1 / 3$ and say 'continue'. The seller continues to the next round when two or three buyers offer $1 / 3$, designating these buyers as active. Otherwise, the seller accepts the highest offer.

Time 1 . The active buyers are those who bid $1 / 3$ in the previous round. These buyers had values $v_{i} \geq 1 / 2$. Given two active buyers, offers correspond to the line traced by squares. Any active buyer $i$ with value $v_{i} \leq 5 / 6$ offers $1 / 2+\left(v_{i}-1 / 2\right) / 2$ and says 'end' while any active buyer with value $v_{i}>5 / 6$ offers $2 / 3$ and says 'continue'. The inactive buyer $j$ again says 'end'. The seller accepts the highest offer unless both active buyers offer $2 / 3$. In that case, the game continues and these buyers remain active. Given three active buyers, offers correspond to the line traced by unfilled dots. Each active buyer $i$ offers $1 / 2+2\left(v_{i}-1 / 2\right) / 3$ and says 'end'. The seller accepts the highest offer.

Time 2. This round is only reached if two buyers had values greater than $5 / 6$ and the third buyer had value less than $1 / 2$. Offers now correspond to the line traced by $\times$. Active buyers offer $5 / 6+\left(v_{i}-5 / 6\right) / 2$ and say 'end'. The inactive buyer again says 'end'. The seller accepts the highest offer. The game never continues to time 3 .

Losses due to delay. The second round is reached if two or more buyers have values greater than $1 / 2$, which happens half of the time given three buyers. The third round is reached only when one buyer has value less than $1 / 2$ and the other two have values greater than $5 / 6$, which happens with probability $3(1 / 2)(1 / 6)^{2}=1 / 24$. Thus, expected total delay costs are $1 / 6(1 / 2+1 / 24)=13 / 144 \approx .0903$. An efficient auction raises expected revenue $1 / 2$ and creates expected total surplus $3 / 4$. Thus, equilibrium losses due to delay amount to about $18 \%$ of the revenue or $12 \%$ of the total gains from trade in an efficient auction. 
Other observations. A few aspects of this example are noteworthy. (a) The seller's net revenue is never higher than in a first-price auction, in which each buyer offers $2 v_{i} / 3$. (When $\max _{i} v_{i} \leq 1 / 2$ or $\min _{i} v_{i} \geq 1 / 2$, the seller gets the same ex post net revenue as in a first-price auction. Otherwise, the seller gets strictly less.) (b) Every active buyer at time $T+1$ offers at least $c(T)$ more at time $T+1$ than he did at time $T$. (c) In every round, every inactive buyer's value is less than every active buyer's offer. Furthermore, the object is sold to the buyer with the highest value.

Intuition for the proof of Theorem 1. We will focus here on providing intuition for why no player prefers to deviate along the equilibrium path of play. The proof in the Appendix provides a formal treatment.

Buyers' offers. It is useful to distinguish three sorts of offers at each time $T$ : the continuation offer, terminal offers, and unexpected offers. In these terms, the game unfolds in the same way for every buyer. (i) For several rounds, make the continuation offer and say 'continue'. In each such round, the buyer either wins the object or remains active in the next round. (ii) Eventually, in exactly one round (if reached), make a terminal offer and say 'end'. If the buyer does not win the object in this round, he will become and remain inactive in all future rounds. (iii) Thereafter, say 'end'.

'The continuation offer'. High buyer types pool by all offering $s_{T} \equiv \underline{v}_{T}+\left(M_{T}-1\right)(R+$ $c(T)$, which we refer to as 'the continuation offer'. Any buyer who makes the continuation offer will win the object immediately if all others offer less; otherwise, the game continues to the next round. The lowest buyer type who makes this offer has value $\underline{v}_{T}+M_{T}(R+c(T)) \equiv$ $\underline{v}_{T+1}=s_{T}+R+c(T)$. (This lowest continuing type shades his bid by exactly $R+c(T)$ below his value.)

'Terminal offers'. A terminal offer at time $T$ is any offer less than the continuation offer. 
Any buyer who makes a terminal offer in round $T$ will either win the object immediately or be certain not to win at any later time. Consequently, any such buyer views the game as 'ending' at time T. Perhaps not surprisingly, then, every terminal offer is equal to the bid that one would have made in a first-price auction when faced with the same set of opponents.

This connection with first-price auctions is central to our analysis. Let $b_{F P A}(\cdot ; M,[\underline{v}, \bar{v}])$ denote the (unique symmetric pure) equilibrium strategy in the first-price auction with $M$ bidders having values drawn i.i.d. uniform from $[\underline{v}, \bar{v}]$ :

$$
b_{F P A}(v ; M,[\underline{v}, \bar{v}])=\underline{v}+(v-\underline{v}) \frac{M-1}{M} \text { for all } v \in[\underline{v}, \bar{v}]
$$

To see the connection, observe that

$$
\begin{array}{rlr}
s_{T} & =b_{F P A}\left(\underline{v}_{T+1} ; M_{T},\left[\underline{v}_{T}, \bar{V}\right]\right) & \text { (continuation offer) } \\
b_{i, T} & =\min \left\{s_{T}, b_{F P A}\left(v_{i} ; M_{T},\left[\underline{v}_{T}, \bar{V}\right]\right)\right\} & \text { (active buyer's offer) }
\end{array}
$$

(The seller and all buyers know at the beginning of round $T$ what the lowest buyer value $\underline{v}_{T+1}$ will be if round $T+1$ is reached since $\underline{v}_{T+1}$ only depends on $\underline{v}_{T}, M_{T}, R, c(T)$.)

'Unexpected offers'. Any offer greater than the continuation offer is an unexpected offer and does not occur in equilibrium.

Beliefs. Next we sketch equilibrium beliefs, both on and off the equilibrium path. (See the Appendix for details.) Let $b_{T}^{(1)}$ denote the highest offer made in round $T$ and define $v_{T}^{(1)} \equiv b_{F P A}^{-1}\left(b_{T}^{(1)} ; M_{T},\left[\underline{v}_{T}, \bar{V}\right]\right) . v_{T}^{(1)}$ is the value given which a bidder would have bid $b_{T}^{(1)}$ in the first-price auction corresponding to round $T$ of our game. Players' belief about buyer $i$ 's value at the end of round $T$ depends only on the highest offer $b_{T}^{(1)}$ and on whether buyer $i$ said 'end' or 'continue' in round $T$.

Buyer $i$ offered $b_{T}^{(1)}$ or said 'continue'. If $b_{T}^{(1)}$ is a terminal offer, players believe that $v_{i}=v_{T}^{(1)}$. If it is the continuation offer, players believe that $v_{i} \in\left[v_{T}^{(1)}, \bar{V}\right]$, where $v_{T}^{(1)}=$ 
$b_{T}^{(1)}+R+c(T)$. (This relationship follows by construction of the continuation offer.) If it is an unexpected offer, finally, players believe that $\left.v_{i} \in\left[b_{T}^{(1)}+R+c(T), \bar{V}\right]\right]_{18}^{18}$ (In this case, by construction, all players believe that bidder $i$ shaded his bid by more than $R+c(T)$ below his value.)

Buyer $i$ offered less than $b_{T}^{(1)}$ and said 'end'. If $b_{i, T}$ is a terminal offer, players believe that $v_{i}=b_{F P A}^{-1}\left(b_{i, T} ; M_{T},\left[\underline{v}_{T}, \bar{V}\right]\right)$. For the continuation offer or an unexpected offer to be less than $b_{T}^{(1)}$, some other buyer must have made a higher unexpected offer. Given that buyer $i$ says 'end' in this case, players believe that $v_{i} \in\left[b_{i, T}+R+c(T), b_{T}^{(1)}+R+c(T)\right]$.

Discussion. Players only expect a buyer to say 'continue' if his value exceeds the minimal inferred value of the highest bidder. In particular, any buyer who is inactive or makes a terminal offer in round $T$ is expected to say 'end'. If such a buyer instead says 'continue', players ignore his past behavior and infer that his value is drawn from the same interval as that of the highest bidder. Going into the next round, then, all active buyers are believed to be symmetric, even after such a surprise.

The seller's problem. When the highest offer is terminal. By construction, when $b_{T}^{(1)}$ is a terminal offer, all buyers' values are less than $b_{T}^{(1)}+R+c(T)$. Thus, in the future no buyer will never be willing to pay enough to justify the seller's soliciting another round of offers. (Doing so leads the seller to incur extra delay $\operatorname{cost} c(T)$ and lose a reputation worth $R$.) The seller's best response is to accept the highest current offer.

When exactly one buyer makes the continuation offer. Suppose that buyer 1 makes the continuation offer $s_{T}$ but all others make terminal offers. If play were to proceed to round $T+1$, buyer 1 would know that all others have values strictly less than $s_{T}+R+c(T)$. All buyers $i \neq 1$ will therefore offer at most $s_{T}+R+c(T)$ in any future period, as must buyer

\footnotetext{
${ }^{18}$ If the unexpected offer is so high that $b_{T}^{(1)}+R+c(T)>\bar{V}$, then players believe that $v_{i}=\bar{V}$.
} 
1 in any best response. In this case, again, the seller prefers not to incur $\operatorname{costs} R+c(T)$ by proceeding to round $T+1$. The seller's best response is to accept the highest current offer.

When two or more buyers make the continuation offer. Players infer that any buyer who makes the continuation offer must have value greater than $s_{T}+R+c(T)$. Competition between remaining active buyers will lead them all to offer at least $s_{T}+R+c(T)$ in round $T+1$. The seller therefore prefers to proceed to round $T+1,19$ The seller is willing to inactivate all buyers who offered less than $s_{T}$ (and said 'end') since she believes that their values are strictly less than $s_{T}+R+c(T)$ and hence that they will have no effect on future bidding competition.

The buyer's problem. Consider any offer $\tilde{b}$ for buyer $i$ in round $T$. Buyer $i$ will win immediately at time $T$ iff $\max _{j \neq i} v_{j, T}<v(\tilde{b})$ where

$$
\begin{aligned}
v(\tilde{b}) & \equiv b_{F P A}^{-1}\left(b ; M_{T},\left[\underline{v}_{T}, \bar{V}\right]\right) \text { if } \widetilde{b} \leq s_{T} \\
& \equiv \tilde{b}+R+c(T) \text { if } \widetilde{b} \geq s_{T}
\end{aligned}
$$

Conditional on winning immediately, of course, buyer $i$ will pay $\tilde{b}$. By a basic fact about first-price auction strategies, for all $\tilde{b} \leq s_{T}$,

$$
\tilde{b}=b_{F P A}\left(v(\tilde{b}) ; M_{T},\left[\underline{v}_{T}, \bar{V}\right]\right)=E\left[\max _{j \neq i} v_{j, T} \mid \max _{j \neq i} v_{j, T}<\tilde{v}\right]
$$

Thus, conditional on winning with a terminal or continuation offer, buyer $i$ will pay the expected highest value of any other buyer. Similarly, if buyer $i$ makes an unexpected offer $\tilde{b}>s_{T}, \tilde{b}>b_{F P A}\left(v(\tilde{b}) ; M_{T},\left[\underline{v}_{T}, \bar{V}\right]\right) .20$ Thus, conditional on winning with an unexpected

\footnotetext{
${ }^{19}$ The seller would prefer to proceed to round $T+1$ even if her reputation would be lost by doing so. In fact, since buyers expect the seller to solicit another round of offers in this scenario, her reputation is not lost. This further strengthens the seller's incentive to continue.

${ }^{20}$ By construction, if $\tilde{b}$ is an unexpected offer, then $b_{F P A}^{-1}\left(\tilde{b} ; M_{T},\left[\underline{v}_{T}, \bar{V}\right]\right)>\tilde{b}+R+c(T)$. This implies that $\tilde{b}>b_{F P A}\left(\tilde{b}+R+c(T) ; M_{T},\left[\underline{v}_{T}, \bar{V}\right]\right)$.
} 
offer, buyer $i$ will pay more than the expected highest value of any other buyer.

Similar logic shows that (i) if buyer $i$ wins with a terminal or continuation offer at a later time, he will pay the expected highest value of any other buyer and (ii) if buyer $i$ wins with an unexpected offer at a later date, he will pay more than the expected highest value of any other buyer. (See the induction argument in the Appendix.) Point (i) establishes that buyer $i$ 's expected equilibrium payoff is $\operatorname{Pr}\left(v_{i}>\max _{j \neq i} v_{j, T}\right) E\left[v_{i}-\max _{j \neq i} v_{j, T} \mid v_{i}>\max _{j \neq i} v_{j, T}\right] \cdot{ }^{21}$ Point (ii) establishes that buyer $i$ 's expected surplus from any deviation at time $T$ is at most $\operatorname{Pr}(i$ wins $) E\left[v_{i}-\max _{j \neq i} v_{j, T} \mid i\right.$ wins $]$, where ' $i$ wins' is the event in which buyer $i$ wins at time $T$ or some later date. This is maximized when buyer $i$ wins iff $v_{i}>\max _{j \neq i} v_{j, T}$. Consequently, no deviation can increase buyer $i$ 's expected payoff.

\subsection{Many rounds of offers: English auction?}

When the seller has little reputation and per-round delay costs are small, our game appears very similar to an English auction. The price rises over time in equilibrium, and bargaining continues so long as two or more buyers express willingness to pay more than the current price. Yet there are also important differences. First, the auctioneer specifies the pace at which price increases over time in the English auction; in our game, this pace is endogenous and changes over time as the per-round cost of delay and/or the number of active bidders changes. Second, there are no costs associated with running an English auction (other than fixed costs); in our game, the seller may incur additional costs with every round of offers.

Pace of offers. Suppose that round $T$ is reached in equilibrium after a history with

\footnotetext{
${ }^{21}$ As an implication of the Revenue Equivalence Theorem, this is the same expected equilibrium payoff that a bidder with value $v_{i}$ gets in a first-price auction with $M_{T}$ bidders whose values are drawn i.i.d. uniform from $\left[\underline{v}_{T}, \bar{V}\right]$.
} 
$\left(M_{0}, \ldots, M_{T-1}\right)$ active buyers in previous rounds. All offers in round $T$ will fall in the range $\left[\underline{b}_{T}, \bar{b}_{T}\right]$, where

$$
\begin{aligned}
& \underline{b}_{T} \equiv \underline{V}+\sum_{T^{\prime}=0}^{T-1} M_{T^{\prime}}\left(R+c\left(T^{\prime}\right)\right) \\
& \bar{b}_{T} \equiv s_{T}=\underline{b}_{T}+\left(M_{T}-1\right)(R+c(T))
\end{aligned}
$$

and $s_{T}$ is the continuation offer in round $T$. A few noteworthy observations:

1. $\bar{b}_{T-1}+R+c(T-1)=\underline{b}_{T}$, i.e. all offers made in round $T$ exceed all offers made in round $T-1$ by at least $R+c(T-1)$.

We will refer to $s_{T}-s_{T-1}$ as the 'pace' of equilibrium offers.

2. Pace is decreasing over time if $c(T)$ is decreasing in $T$. (This result exploits the fact that the number of active bidders is non-increasing over time.)

3. Pace is increasing over time if $c(T)$ is strictly increasing in $T$ until some buyer drops out, then increases again until another buyer drops out, etc.

For notational simplicity, we shall restrict attention in the rest of this section to the case in which $c(T)=c$ for all $T$.

Seller bears delay cost. In equilibrium, the buyer with the highest value always wins the object and any buyer with the lowest value gets zero surplus. By the Revenue Equivalence Theorem, then, the seller's gross expected revenue (and each buyer's expected surplus) must be the same as in an efficient auction such as a first-price auction with zero reserve price. Thus, the seller bears all equilibrium delay costs in the form of lost profits. Let $\Pi(R, c, N)$ be the seller's expected equilibrium net revenue and $\phi(R, c, N)$ the expected total delay cost in our game, and let $\Pi_{E F F}(N)$ be the seller's expected profit in an efficient auction. Then $\Pi(R, c, N)=\Pi_{E F F}(N)-\phi(R, c, N)$. 
What more can we say about $\frac{\phi(R, c, N)}{\Pi_{E F F}(N)}$, the percentage of lost revenues relative to an efficient auction? (Percentage losses relative to an optimal mechanism will of course be even greater.) Consider the case in which per-round delay costs and reputation are so small as to appear negligible. Seller losses in this case may or may not be negligible, depending on whether the seller's reputation is large or small relative to the per-round cost of delay.

Theorem 2 (Percentage losses for small delay costs and reputation). Consider a sequence $\left\{\left(R^{k}, c^{k}\right)\right\} \searrow(0,0)$ such that $\frac{R^{k}}{c^{k}}=\chi$ fixed.

$$
\lim _{k \rightarrow \infty} \frac{\phi\left(R^{k}, c^{k}, N\right)}{\prod_{E F F}(N)}=\frac{\sum_{k=2}^{N} \frac{1}{k}}{(\chi+1)(N-1)}
$$

Like an English auction ... To interpret Theorem 2, suppose first that the value of the seller's reputation is large relative to per-round delay costs, $R>>c$. In this case, $\chi \approx \infty$ and the seller's inability to commit to a sales mechanism leads to negligible lost profit. This case can be thought of as being essentially like an English auction, though with an endogenous pace for prices.

Indeed, consider the extreme case when $c(T)=0$. As long as the seller has any reputation whatsoever for leaving money on the table $(R>0)$, the negotiation will proceed as if in an ascending-price auction in which the auctioneer requires every new bid to be at least $R$ higher than the highest previous bid.

... or not. On the other hand, if $c>>R$, equilibrium losses due to delay can be quite significant. Exact percentage losses due to delay are available in closed form for the case of two buyers. (Computations are much more difficult for $N>2$ and appear to offer no new insight.) In particular, the game proceeds to round $T$ exactly when both buyers have types greater than $2(R+c) T$, which happens with probability $(1-2(R+c) T)^{2}$. Since each round 


\begin{tabular}{|c|c|c|c|c|c|c|}
\hline \# Per-round delay cost & .01 & .025 & .05 & .1 & .25 & .5 \\
\hline \% Lost $(R=0)$ & $48.5 \%$ & $46.3 \%$ & $42.8 \%$ & $36.0 \%$ & $18.8 \%$ & $0 \%$ \\
\hline \% Lost $(R=.1)$ & $4.4 \%$ & $9.3 \%$ & $14.3 \%$ & $18.0 \%$ & $13.4 \%$ & $0 \%$ \\
\hline
\end{tabular}

Table 1: \% lost revenue relative to a standard efficient mechanism given two buyers.

has delay cost $c$, total delay cost is

$$
\phi(R, c, 2)=c\left(\sum_{T=1}^{\left\lfloor\frac{1}{2(R+c)}\right\rfloor}(1-2(R+c) T)^{2}\right)
$$

Table 1 displays a few specific values of $\phi(R, c, 2)$ for different levels of reputation $R$ and per-round delay cost $c$. It is easy to check that $\phi(R, c, 2)$ is strictly decreasing in $(R, c)$ whenever $R+c<1 / 2$ and equal to zero whenever $R+c \geq 1 / 2$. This yields a corollary to Theorem 2 ,

Corollary. When $N=2$, the seller's expected profit is non-decreasing in $(R, c)$ and strictly decreasing when $R+c<1 / 2$.

\section{Changing the game}

The analysis of Section 2 showed why, in some situations, a seller can not credibly commit not to expend considerable resources attempting to extract higher offers from buyers. Of course, in such settings we would not expect the seller to play our game, since the losses relative to an efficient auction are substantial. (The losses relative to an optimal auction are even greater.) A seller's difficulty creates an opportunity for a third-party to profit by helping to sell the object.

There are several distinct and potentially important ways in which an intermediary can help a seller change the game. 
'Keep bids sealed'. In some instances, the seller has discretion over whether to reveal buyers' offers. If the seller can credibly commit not to reveal any information about these offers, then buyers will ignore any communication from the buyer as cheap talk and not increase their initial offers. Keeping bids secret therefore allows one to run a first-price auction. This is not always possible. For instance, publicly-traded companies are required to disclose acquisition offers.

'Lazy intermediary'. Another possibility is to credibly delegate the entire sales process to an agent in exchange for a fixed wage $W>0$. We call such an agent a lazy intermediary because he has no incentive to reveal buyers' offers, to solicit more offers to get a higher price, etc. He will simply accept the highest buyer offer made at time 0 . Anticipating this, the buyers view their interaction with this intermediary as a first-price auction with zero reserve price and bid accordingly. A lazy intermediary has no incentive to act in the seller's best interest, but this is precisely what induces the buyers to make serious offers immediately.

In principle, a lazy intermediary does not need to have any reputation to run an auction. Crucial to such an intermediary's success, however, is the ability to sign a binding contract with the seller (i) paying the intermediary a fixed fee and (ii) giving the intermediary control over the entire sales process. In practice, a seller might attempt to re-contract with the intermediary and/or refuse to sell the object for the price or to the buyer specified by the intermediary. To alleviate these concerns, it must be costly for the intermediary and/or for the seller when the highest initial offer is not accepted.

Reputable intermediary. Suppose first that the agent can costlessly re-negotiate his fee with the seller while negotiating with the buyers. Anticipating this, buyers expect the intermediary to act so as to maximize the seller and intermediary's joint profit.

Assume that an active intermediary conducts $K$ sales per year of objects having value in 
$[\underline{V}, \bar{V}]$, has profit $\pi$ per sale, and discount rate $\delta<1$. The present value of his reputation is $\pi K \frac{\delta}{1-\delta}$. Assuming that the intermediary will lose his entire reputation if he negotiates further with buyers, the intermediary can credibly commit to hold a first-price auction on the seller's behalf whenever

$$
\frac{K \pi \delta}{1-\delta} \geq \frac{\bar{V}-\underline{V}}{n}
$$

To see why, recall that each buyer offers $\underline{V}+\left(v_{i}-\underline{V}\right) / n$ if he believes that a first-price auction is being held. The most that any buyer is willing to pay in addition to this offer is $(\bar{V}-\underline{V}) / n$. The intermediary loses more than this by reneging on his promise to hold an auction, however, so there is no way for the seller and intermediary to increase their joint profit by re-contracting.

Note that the minimal reputation needed to credibly conduct a first-price auction increases linearly with the extent of uncertainty surrounding the object's value. To sell an object worth between $\$ 0$ and $\$ 2,000,000$, an intermediary needs to sell twice as many of them (double $K$ ), make twice as much profit per sale (double $\pi$ ), be twice as patient (halve $\left.\frac{\delta}{1-\delta}\right)$ or attract twice as many buyers as he needs to sell an object worth between $\$ 1,000,000$ and $\$ 2,000,000$.

Firing costs. Suppose next that the agent does not have complete control over the sales process. In particular, suppose that after observing the negotiation between the intermediary and the buyers, the seller has the right to 'fire' the intermediary at cost $F>0$ and continue negotiating with the buyers herself. This firing fee could be a contractual cost but need not be. A contract with an intermediary such as a real estate broker or investment bank typically stipulates that a seller is liable for commission if he fires the intermediary and later sells to one of the buyers found by the intermediary. Furthermore, there may be other costs associated with firing an intermediary. For example, a number of services associated with 
finalizing a transaction are included in the commission. By firing an intermediary before the transaction is complete, the seller loses the value of these services.

Hiring an intermediary with such a firing fee leads to buyer offers that rise at a faster pace than if the seller conducted the entire negotiation on her own. In particular, offers rise at the same pace as if the seller had reputation equal to her own reputation plus the firing fee. (In equilibrium, furthermore, the seller never fires the intermediary.) This reduces equilibrium losses due to delay and hence increases the seller's expected profit gross of any commission paid to the intermediary.

\section{Concluding Remarks}

When it is costly for players to 'bend the rules' in their favor, we can expect significant resources to be spent and lost in this way. In this paper, we consider a relatively simply question along these lines: "What happens when a seller can not commit to a first-price auction?" If the seller can trick the buyers into believing that she will definitely accept the highest offer, then the seller will make more than in an auction. Given sophisticated buyers who understand the seller's incentives, however, the seller is always worse off than in an auction. Indeed, equilibrium losses can be substantial unless the cost of soliciting another round of offers is either very large (when she can credibly commit to a first-price auction) or very small (when the outcome approximates that of an English auction).

Separate commitment problems loom large for different sorts of auction mechanisms. For example, a seller attempting to conduct a second-price auction may not be able to credibly commit not to hire a shill bidder. More broadly, there are many ways that sellers and/or bidders may bend or break the rules of an auction that deserve future study. For instance, Klemperer (2002) argues that "Ascending auctions are particularly vulnerable to 
rule-breaking by the bidders since they necessarily pass through a stage where there is just one (or a few) excess bidders". During this final stage of the auction, each bidder has a strong incentive to drive others from active bidding while the seller has a strong incentive to keep them in the game. This may lead to all sorts of costly behavior.22 Intermediaries can create value by establishing an environment that deters such gamesmanship.

\footnotetext{
${ }^{22}$ In one remarkable example in the Netherlands 3G auction documented by Klemperer (2002), bidder Telfort successfully induced bidder Versatel to exit by threatening to sue Versatel for driving up the price!
} 


\section{Appendix}

\subsection{Proof of Theorem 1}

Preliminaries. Subgame equilibrium strategies are closely related to equilibrium strategies in a first-price auction. For this reason, the following definitions are useful.

Definition 1 ( $\theta$-first-price auction). Let $\theta=(M,[\underline{v}, \bar{v}])$. The ' $\theta$-first-price auction' is a first-price auction with $M$ bidders having private values drawn i.i.d. from the interval $[\underline{v}, \bar{v}]$ with density $g(v)=\frac{f(v)}{\int_{\underline{v}}^{v} f(s) \mathrm{d} s}$.

$g(v)$ is the density induced by Bayes' Rule from the original density over types for all $[\underline{v}, \bar{v}]$.

Definition 2 ( $\theta$-first-price auction equilibrium strategy). For all $v \in[\underline{v}, \bar{v}], b_{F P A}(v ; \theta) d e$ notes the (unique, pure, symmetric, strictly increasing, continuous) equilibrium bid made by a bidder having value $v$ in the $\theta$-first-price auction. For convenience, we also augment this strategy for other values: let $b_{F P A}(v ; \theta)=v$ for all $v<\underline{v}$ and let $b_{F P A}(v ; \theta)=b_{F P A}(\bar{v} ; \theta)$ for all $v>\bar{v}$.

Tie-breaking rule. We will consider an equilibrium with the following tie-breaking rule. (Since the seller gets the same price regardless of who wins, any tie-breaking rule is obviously incentive-compatible for the seller.) If there is a tie and the seller decides to sell the object, whoever has submitted the highest 'tie-breaking number' wins, followed by coin-flip if these numbers are identical 23

\footnotetext{
${ }^{23}$ This detail of the analysis does not play an important role in our equilibrium, but serves to eliminate the following 'collusive strategies' which can constitute an equilibrium under a simple coin-flip rule: All buyers offer zero and the seller accepts, choosing the winner by coin-flip. If some buyer deviates by offering $\epsilon>0$, the seller does not accept and instead solicits another round of offers. In this continuation game, buyers play more 'competitive strategies' corresponding to our equilibrium.
} 
Definition 3 (Tie-breaking number). During each round T, buyer $i$ announces both an offer $b_{i, T}$ as well as a 'tie-breaking number' $x_{i, T} \in\{0,1, \ldots, N\}$.

(We shall specify both buyer offers and tie-breaking numbers when specifying strategies later.)

State of the game and beliefs. Subgame continuation play starting at the beginning of round $T$ depends on a state $\theta_{T} \equiv\left(M_{T},\left[\underline{v}_{T}, \bar{v}_{T}\right]\right)$ that is common knowledge among all of the players, where $M_{T}$ the number of active buyers and $\left[\underline{v}_{T}, \bar{v}_{T}\right]$ is the 'inferred value interval' for all active buyers. At the beginning of the game $T=0, M_{0}=N$, and $\left[\underline{v}_{0}, \bar{v}_{0}\right]=[\underline{V}, \bar{V}]$.

Buyer offers. When $M_{T}=1$, the (sole) active buyer $i$ offers zero and the seller accepts. When $M_{T}>1$, describing active buyers' offers requires some preparation.

Definition 4 ('Value bounds'). For every value $v_{i} \in\left[\underline{v}_{T}, \bar{v}_{T}\right]$, define

$$
\begin{aligned}
& l\left(v_{i} ; \theta_{T}\right) \equiv \max \left\{v \in\left[\underline{v}_{T}, v_{i}\right]: v-b_{F P A}\left(v ; \theta_{T}\right) \leq c(T)\right\} \\
& h\left(v_{i} ; \theta_{T}\right) \equiv \min \left\{v \in\left[v_{i}, \bar{v}_{T}\right]: v-b_{F P A}\left(v ; \theta_{T}\right) \leq c(T)\right\}
\end{aligned}
$$

$\left(\left\{v \in\left[\underline{v}_{T}, v_{i}\right]: v-b_{F P A}\left(v ; \theta_{T}\right) \leq c(T)\right\}\right.$ is non-empty since $b_{F P A}\left(\underline{v}_{T} ; \theta_{T}\right)=\underline{v}_{T}$. By convention, let $h\left(v_{i} ; \theta_{T}\right) \equiv \bar{v}_{T}$ if $\left\{v \geq v_{i}: v-b_{F P A}\left(v ; \theta_{T}\right) \leq c(T)\right\}$ is empty.)

Discussion: $l\left(v_{i} ; \theta_{T}\right)=v_{i}=h\left(v_{i} ; \theta_{T}\right)$ iff a bidder with value $v_{i}$ shades his bid by less than or equal to the cost of delay $c(T)$ in the $\theta_{T}$-first-price auction. Otherwise $l\left(v_{i} ; \theta_{T}\right)$ (and $h\left(v_{i} ; \theta_{T}\right)$ ) is the highest lower value (and lowest higher value) given which a bidder shades his bid by exactly $c(T)$ in this auction.

Now, when $M_{T}>1$, every active buyer $i$ offers

$$
b\left(v_{i} ; \theta_{T}\right)=b_{F P A}\left(l\left(v_{i} ; \theta_{T}\right) ; \theta_{T}\right) \text { for all } v_{i}
$$


As for the 'tie-breaking numbers' $x_{i}$, every buyer submits $x_{i}=0$ if $\underline{v}_{T}<\bar{v}_{T}$. Otherwise, when $\underline{v}_{T}=\bar{v}_{T} \equiv v_{T}$, buyer $i$ submits $x_{i}=0$ when $v_{i} \leq v_{T}$ and $x_{i}=i \in\{1, \ldots, N\}$ when $v_{i}>v_{T}$.

It is useful to distinguish three sorts of offers. (1) When $l\left(v_{i} ; \theta_{T}\right)=v_{i}$, the offer $b\left(v_{i} ; \theta_{T}\right)$ is a terminal offer. (2) When $l\left(v_{i} ; \theta_{T}\right) \neq v_{i}$, the offer $b\left(v_{i} ; \theta_{T}\right)$ is a continuation offer. (3) Any other offer is an unexpected offer.

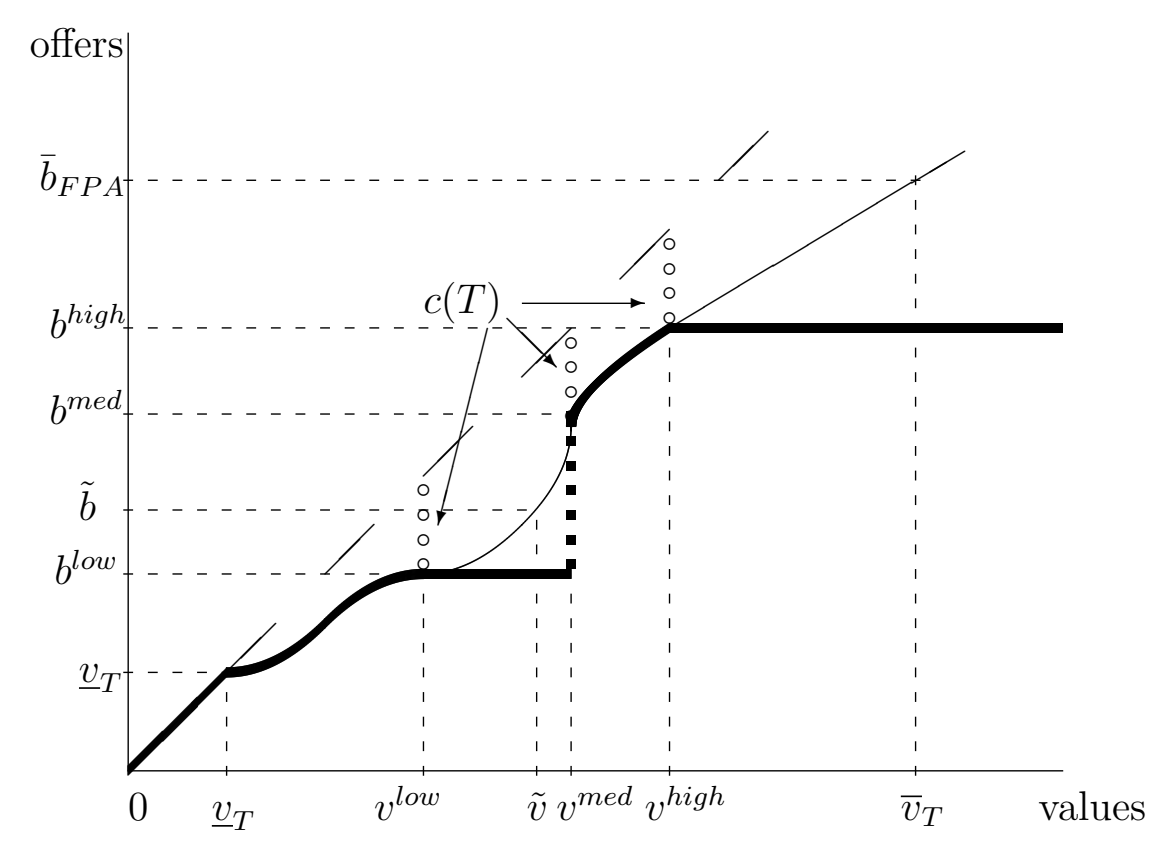

Figure 3: Equilibrium offers by active buyers.

Illustration. Figure 3 illustrates the construction so far. The thick line is the buyers' equilibrium offer strategy in a subgame having state $\theta_{T}$. There are two continuation offers, $b^{\text {low }}$ and $b^{\text {high }}$. For future reference, note that each continuation offer is more than $c(T)$ below the buyer's true value whenever he makes that offer. The terminal offers are all those less than $b^{\text {low }}$ and those between $b^{\text {med }}$ and $b^{\text {high }}$ (including $b^{\text {med }}$ ). Whenever buyer $i$ makes a terminal offer, he acts as if bidding in the $\theta_{T}$-first-price auction. This is why the thick line 
sometimes coincides with the thin line that depicts the equilibrium bidding strategy in the $\theta_{T}$-first-price auction. For future reference, note that each terminal offer is less than $c(T)$ below the buyer's true value when he makes that offer. The unexpected offers are all those between $b^{\text {low }}$ and $b^{\text {med }}$ and those greater than $b^{\text {high }}$.

The interval $\left[l\left(v_{i} ; \theta\right), h\left(v_{i} ; \theta\right)\right]$ captures how much buyer $i$ 'reveals about himself' by making any terminal or continuation offer. (Unexpected offers will be discussed later.) Since only one type makes any given terminal offer, making such an offer perfectly reveals $v_{i}$. In particular, all players infer from a terminal offer $b$ that $v_{i}=b_{F P A}^{-1}\left(b ; \theta_{T}\right)$, so that $l\left(v_{i} ; \theta\right)=h\left(v_{i} ; \theta\right)=b_{F P A}^{-1}\left(b ; \theta_{T}\right)$. Since an interval of types makes each continuation offer, all that a buyer reveals when making such an offer is that his value lies in that interval. By construction, the bounds on this interval are $l\left(v_{i} ; \theta\right)$ and $h\left(v_{i} ; \theta\right)$, the closest types above and below $v_{i}$ who would shade their bids by exactly $c(T)$ in the $\theta_{T}$-first-price auction.

Inferred values. Let $b_{T}^{(1)}$ denote the highest offer in round $T$ given state $\theta_{T}$. Players update their beliefs about buyers' values based on both their offers and their decision whether to says 'end' or 'continue'. First, consider any buyer (call him $j$ ) who offers $b_{j, T}<b_{T}^{(1)}$ and announces 'end'. All other players believe that buyer $j$ 's value is drawn from $\left[\underline{v}_{j, T+1}, \bar{v}_{j, T+1}\right]$ with density induced from the original distribution by Bayes' Rule, where

$$
\begin{aligned}
\underline{v}_{j, T+1} & \equiv b_{F P A}^{-1}\left(b_{j, T} ; \theta_{T}\right) \text { if } b_{j, T} \text { terminal or continuation offer } \\
& \equiv b_{j, T}+R+c(T) \text { if } b_{j, T} \text { continuation or unexpected offer } \\
\bar{v}_{j, T+1} & \equiv \sup \left\{v \leq \underline{v}_{T+1}: b\left(v ; \theta_{T}\right) \leq b_{j, T}\right\}
\end{aligned}
$$

Next, consider any buyer (call him $i$ ) who either makes the high bid $b_{i, T}=b_{T}^{(1)}$ or says 'continue'. All other players believe that buyer $i$ 's value is drawn from $\left[\underline{v}_{i, T+1}, \bar{v}_{i, T+1}\right]$ with 
density induced from the original distribution by Bayes' Rule, where ${ }^{24}$

$$
\begin{aligned}
\underline{v}_{T+1} & \equiv b_{F P A}^{-1}\left(b_{T}^{(1)} ; \theta_{T}\right) \text { if } b_{T}^{(1)} \text { terminal or continuation offer } \\
& \equiv b_{T}^{(1)}+R+c(T) \text { if } b_{T}^{(1)} \text { continuation or unexpected offer } \\
\bar{v}_{T+1} & \equiv \sup \left\{v \leq \bar{v}_{T}: b\left(v ; \theta_{T}\right) \leq b_{T}^{(1)}\right\}
\end{aligned}
$$

Note that players believe buyer $j$ is certain to have a lower value than buyer $i$. (By construction, $\underline{v}_{j, T+1} \leq \bar{v}_{j, T+1} \leq \underline{v}_{i, T+1}$.) This is why the seller is willing to inactivate buyer $j$ in round $T+1$ (see below). Also, given the seller's activation rule (see below), all buyers who are active in round $T+1$ have the same inferred value interval: $\underline{v}_{i, T+1}=\underline{v}_{T+1}$ and $\bar{v}_{i, T+1}=\bar{v}_{T+1}$. In particular, all buyers who are active in round $T+1$ are believed to be symmetric, even after any sort of buyer deviation(s) in round $T$.

Illustration continued. Here we continue to refer to Figure 3. Terminal offers. When the highest current offer $b_{T}^{(1)}$ is a terminal offer, $\underline{v}_{T+1}=\bar{v}_{T+1}=b^{-1}\left(b_{T}^{(1)} ; \theta_{T}\right)$. Continuation offers. If $b_{T}^{(1)}$ is the continuation offer $b^{\text {low }}$, the buyer who made this offer will have revealed his type to lie in the interval $\left[\underline{v}_{T+1}, \bar{v}_{T+1}\right]=\left[v^{\text {low }}, v^{\text {med }}\right]$. In equilibrium, furthermore, all buyers with values less than $v^{\text {low }}$ will say 'end' and be inactivated. So, all remaining buyers also have values drawn from this interval. (If out of equilibrium someone were to offer less than $b^{\text {low }}$ but say 'continue', then all players would assume going forward that he is symmetric to the buyers who did offer $b^{\text {low }}$.) Similar remarks apply if $b_{T}^{(1)}=b^{\text {high }}$, except that the inferred value interval is $\left[v^{h i g h}, \bar{v}_{T}\right]$. Unexpected offers. Finally suppose that the highest offer is an unexpected offer, e.g. $b_{T}^{(1)}=\tilde{b} \in\left(b^{\text {low }}, b^{\text {med }}\right)$. The lower bound $\underline{v}_{T+1}$ on all remaining buyers' values is the type that would bid $b_{T}^{(1)}$ in the $\theta_{T}$-first-price auction. The upper bound $\bar{v}_{T+1}$, ${ }^{24} b_{F P A}^{-1}\left(b_{T}^{(1)} ; \theta_{T}\right)$ is not well-defined when $b_{T}^{(1)}>b_{F P A}\left(\bar{v}_{T} ; \theta_{T}\right)$ or when $b_{T}^{(1)}<b_{F P A}\left(\underline{v}_{T} ; \theta_{T}\right)$. Furthermore, $\sup \left\{v \leq \bar{v}_{T}: b\left(v ; \theta_{T}\right) \leq b_{T}^{(1)}\right\}$ is not well-defined when $b_{T}^{(1)}<b_{F P A}\left(\underline{v}_{T} ; \theta_{T}\right)$. In the first case, define $\underline{v}_{i, T+1} \equiv$ $\bar{v}_{T}$. In the second case, define $\underline{v}_{i, T+1}=\bar{v}_{i, T+1} \equiv b_{T}^{(1)}$. 
however, is the same upper bound as if the highest offer had been the continuation offer $b^{\text {low }}$. In words, we assume that players infer from an unexpected offer $\tilde{b}$ that the buyer's value must be (i) high enough that he would have bid at least $\tilde{b}$ in the $\theta_{T}$-first-price auction and (ii) low enough that he should not have made an even higher offer according to his equilibrium strategy. All other buyers who say 'continue' are also believed to have value drawn from the same interval. The crucial simplifying feature of this construction is that, no matter what happens, all buyers who remain active in round $T+1$ are believed to be symmetric.

Seller's decision. The seller solicits another round of offers iff $\underline{v}_{T+1} \geq b_{T}^{(1)}+R+c(T)$ and there are at least two buyers $i_{1}, i_{2}$ such that $\underline{v}_{T+1}=\underline{v}_{i_{1}, T+1}=\underline{v}_{i_{2}, T+1}$.

Theorem 3. The strategies and beliefs described above constitute a perfect Bayesian equilibrium of the Bargaining Game.

Proof. Recall that $\theta_{T} \equiv\left(M_{T},\left[\underline{v}_{T}, \bar{v}_{T}\right]\right)$ denotes the 'state' of a round $T$ subgame with $M_{T}$ active buyers, all of whom are believed to have values drawn i.i.d. from $\left[\underline{v}_{T}, \bar{v}_{T}\right]$ with density induced by Bayes' Rule from the original distribution over $[\underline{V}, \bar{V}]$. We need to show that all players' strategies are best responses given these beliefs.

Part I: Seller best response. Suppose that $\underline{v}_{T+1} \geq b_{T}^{(1)}+R+c(T)$ and there are at least two buyers $i_{1}, i_{2}$ such that $\underline{v}_{T+1}=\underline{v}_{i_{1}, T+1}=\underline{v}_{i_{2}, T+1}$. In this case, the seller expects all such high-value buyers to offer at least $b_{T}^{(1)}+R+c(T)$ in round $T+1$. The seller therefore prefers to solicit another round of offers even if she had promised not to do so. (In fact, the seller promised to continue in this case, so she does not incur the cost $R$.) On the other hand, suppose that $\underline{v}_{T+1}<b_{T}^{(1)}+R+c(T)$ (as when the highest offer is terminal) or there is just one buyer $i^{*}$ such that $\underline{v}_{T+1} \underline{v}_{i^{*}, T+1}$ (as when the highest offer is a continuation offer or unexpected offer but everyone else offers less and says 'end'). In this case, all other buyers 
must have values strictly less than $b_{T}^{(1)}+R+c(T)$. If the game were to continue, buyer $i^{*}$ 's best response would never be to offer more than $b_{T}^{(1)}+R+c(T)$. Consequently, the seller expects to never get enough extra revenue to justify breaking her promise not to continue to round $T+1$ in this case.

Part II: Buyer best response. Checking that each buyer's decision whether to say 'end' or 'continue' is a best response is trivial. Each buyer says 'end' iff he believes he is certain not to win. We focus only on offers here.

If there is only one buyer, offering zero is clearly a best response since the seller will accept. The proof for the case with more than one active buyer is by backwards induction, but requires some preparation.

Attrition in the Bargaining Game. First, note that the set of types who stay in the game shrinks over time. Either $\underline{v}_{T+1}=\bar{v}_{T+1}$ or $\underline{v}_{T+1}>\underline{v}_{T}$. Proof. See Figure 3. By definition of the first continuation offer $v^{\text {low }}, v^{\text {low }}-b^{\text {low }}=d(T)$. Since the offer function is strictly increasing over the range $\left[\underline{v}_{T}, v^{\text {low }}\right]$, however, it must be that $b^{\text {low }}>\underline{v}_{T}$ so that $v^{\text {low }}>\underline{v}_{T}$. So, either $b_{T}^{(1)}<v^{\text {low }}$ in which case $\underline{v}_{T+1}=\bar{v}_{T+1}$ or $\underline{v}_{T+1}>\underline{v}_{T}$.

Recall that, by assumption, time $\bar{T}$ exists such that $\bar{V}-\underline{V}<D(\bar{T})=\sum_{T^{\prime}=0}^{\bar{T}-1} d\left(T^{\prime}\right)$. Thus, the above attrition result implies that, regardless of what strategy buyer $i$ may adopt, $\bar{v}_{\bar{T}}=\underline{v}_{\bar{T}}$ if the game ever proceeds to time $\bar{T}$, in which case the game will end at time $\bar{T}$. 'Inverse offers'. Next, recall that $b\left(v_{i}, \theta_{T}\right)$ denotes the equilibrium offer made at time $T$ in state $\theta_{T}$ given value $v_{i}$. It will be convenient to have shorthand for 'inverse offers'.

Definition 5 (Inverse offers). Let $v\left(b_{i, T} ; \theta_{T}\right) \equiv \sup \left\{v \leq \bar{v}_{T}: b\left(v ; \theta_{T}\right) \leq b_{i, T}\right\}$ with $v\left(b_{i, T}=\bar{v}\right.$ if $b\left(\bar{v} ; \theta_{T}\right)<b_{i, T}$. 
For every state $\theta_{T}$, value $v_{i}$, offer $b_{i, T}$, and subset $X \subset\left[\underline{v}_{T}, \bar{v}_{T}\right]$ define

$$
\Pi\left(v_{i} ; X ; \theta_{T}\right) \equiv \operatorname{Pr}_{\theta_{T}}\left(\max _{j \neq i} v_{j, T} \in X\right) E_{\theta_{T}}\left[v_{i}-\max _{j \neq i} v_{j, T} \mid \max _{j \neq i} v_{j, T} \in X\right]
$$

By construction, $\Pi\left(v_{i} ;\left[0, v_{i}\right] ; \theta_{T}\right)$ is the equilibrium expected surplus of a bidder in the $\theta_{T^{-}}$ first-price auction who has value $v_{i}$. For any fixed $v_{i}$ and $\theta_{T}$, it is clear that

$$
\Pi\left(v_{i} ;\left[0, v_{i}\right] ; \theta_{T}\right)>\Pi\left(v_{i} ; X ; \theta_{T}\right) \text { for all } X \neq\left[0, v_{i}\right]
$$

In terms of this notation, our strategy to verify that buyers play best response is the following. First, if buyer $i$ plays his equilibrium strategy, then his expected continuation surplus at time $T$ in state $\theta_{T}$ is $\Pi\left(v_{i} ;\left[0, v_{i}\right] ; \theta_{T}\right)$. Second, if he deviates at time $T$ (and then follows his equilibrium strategy in continuation play), buyer $i$ 's expected continuation surplus is less than or equal to $\Pi\left(v_{i} ; X ; \theta_{T}\right)$ for some $X \neq\left[0, v_{i}\right]$.

Equilibrium payoff same as in $\theta_{T}$-first-price auction. Suppose that buyer $i$ has value $v_{i}$ and makes his equilibrium offer $b\left(v_{i} ; \theta_{T}\right)=b_{F P A}\left(l\left(v_{i} ; \theta_{T}\right), \theta_{T}\right)$. When $\max _{j \neq i} v_{j, T}<l\left(v_{i} ; \theta_{T}\right)$, buyer $i$ wins immediately and pays $b_{F P A}\left(l\left(v_{i} ; \theta_{T}\right), \theta_{T}\right)=E\left[\max _{j \neq i} v_{j, T} \mid \max _{j \neq i} v_{j, T}<l\left(v_{i} ; \theta_{T}\right)\right]$. When $\max _{j \neq i} v_{j, T}>h\left(v_{i} ; \theta_{T}\right)$, on the other hand, some other buyer has a higher value than buyer $i$, so buyer $i$ will say 'end' and get nothing. Finally, when $\max _{j \neq i} v_{j, T} \in$ $\left(l\left(v_{i} ; \theta_{T}\right), h\left(v_{i} ; \theta_{T}\right)\right)$ the game will continue to the next round. By induction, in this continuation game buyer $i$ will win the object precisely when $\max _{j \neq i} v_{j, T} \in\left[l\left(v_{i} ; \theta_{T}\right), v_{i}\right]$ and on average pay $E\left[\max _{j \neq i} v_{j, T} \mid \max _{j \neq i} v_{j, T} \in\left[l\left(v_{i} ; \theta_{T}\right), v_{i}\right]\right]$. All together, then, buyer $i$ 's equilibrium payoff in our game is simply $\Pi\left(v_{i} ;\left[0, v_{i}\right] ; \theta_{T}\right)$, the same as in the $\theta_{T}$-first-price auction.

All deviations unprofitable. Suppose that buyer $i$ makes some offer $\tilde{b}$. This offer will 
win immediately exactly when $\max _{j \neq i} v_{j, T}<v\left(\tilde{b} ; \theta_{T}\right)$. By construction, furthermore,

$$
\begin{aligned}
\tilde{b} & =E\left[\max _{j \neq i} v_{j, T} \mid \max _{j \neq i} v_{j, T}<v\left(\tilde{b} ; \theta_{T}\right)\right] \text { if } \tilde{b} \text { terminal or continuation offer } \\
& >E\left[\max _{j \neq i} v_{j, T} \mid \max _{j \neq i} v_{j, T}<v\left(\tilde{b} ; \theta_{T}\right)\right] \text { if } \tilde{b} \text { unexpected offer }
\end{aligned}
$$

Buyer $i$ will lose immediately after making offer $\tilde{b}$ if the highest offer exceeds $\tilde{b}$ and is a terminal offer. And buyer $i$ will have the option to continue to the next round if the highest offer is greater than or equal to $\tilde{b}$ and is a continuation offer. (By saying 'continue', buyer $i$ can induce the seller to solicit another round of offers.) In particular, let $Y(\tilde{b}) \subset$ $\left[\underline{v}_{T}, \bar{v}_{T}\right]$ be defined implicitly by $\max _{j \neq i} v_{j, T} \in Y(\tilde{b})$ implies that $\max _{j \neq i} b\left(v_{j, T}, \theta_{T}\right) \geq \tilde{b}$ and $\max _{j \neq i} b\left(v_{j, T}, \theta_{T}\right)$ is a continuation offer. Buyer $i$ will wind up winning the object at a later date whenever $\max _{j \neq i} v_{j, T} \in Y(\tilde{b}) \cap\left[0, v_{i}\right]$ and, on average, pay $E\left[\max _{j \neq i} v_{j, T} \mid \max _{j \neq i} v_{j, T} \in\right.$ $\left.Y(\tilde{b}) \cap\left[0, v_{i}\right]\right]$ when he wins in this way.

All together, buyer $i$ 's expected surplus from deviating with offer $\tilde{b}$ at time $T$ is less than or equal to $\Pi\left(v_{i} ; X ; \theta_{T}\right)$ for $X=\left[0, v\left(\tilde{b} ; \theta_{T}\right)\right] \cup Y(\tilde{b})$. (When $\tilde{b}$ is a terminal or continuation offer, buyer $i$ 's expected surplus equals $\Pi\left(v_{i} ; X ; \theta_{T}\right)$ by 10 . When $\tilde{b}$ is an unexpected offer, buyer $i$ 's surplus is less than $\Pi\left(v_{i} ; X ; \theta_{T}\right)$ by 11 . $)$ This is never better than buyer $i$ 's equilibrium payoff, so each buyer prefers not to deviate.

\subsection{Proof of Theorem 2}

Buyer $i$ remains active until the first round in which his current value does not exceed the continuation offer by $R+c$ or more. (In that round, buyer $i$ will make a terminal offer if his offer is not the highest.) As long as there are $M$ active buyers, continuation offers rise at rate $M(R+c)-d$ per round while values decrease at rate $d$ per round. All together, then, the difference between each buyer's current value and the next continuation offer decreases 
by $M(R+c)$ per round. At time $T=0$, furthermore, the first continuation offer equals $\underline{V}+(N-1)(R+c)$. Given any particular realization of values, then, we can easily compute the actual number of rounds.

Let $v^{(1)} \equiv \max _{i} v_{i}$ denote the highest buyer type, $v^{(2)}$ the second-highest, $\ldots$, and $v^{(N)}$ the lowest. When $R, c \approx 0$, there will be approximately $\frac{v^{(N)}}{N(R+c)}$ rounds until one buyer drops out. Thus, the total delay cost until one buyer drops out is approximately $\frac{v^{(N)}}{N} \frac{c}{R+c}$. With $N-1$ buyers remaining, there will then be approximately $\frac{v^{(N-1)}-v^{(N)}}{(N-1) C}$ more rounds until the second buyer drops out, for extra delay cost $\frac{v^{(N-1)}-v^{(N)}}{(N-1)} \frac{c}{R+c}$. And so on, until only one buyer remains. Given the uniform distribution, of course, $E\left[v^{(N)}\right]=\frac{1}{N+1}, E\left[v^{(N-1)}\right]=\frac{2}{N+1}, \ldots$, and $E\left[v^{(2)}\right]=\frac{N-1}{N+1}$. Thus, expected total delay cost

$$
\lim _{k \rightarrow \infty} \phi\left(R^{k}, c^{k}, N\right)=\frac{\sum_{m=2}^{N} \frac{1}{m}}{N+1} \lim _{k \rightarrow \infty} \frac{c^{k}}{R^{k}+c^{k}}=\frac{1}{1+\chi} \frac{\sum_{m=2}^{N} \frac{1}{m}}{N+1}
$$

where, recall, $\chi \equiv \lim _{k \rightarrow \infty} \frac{R^{k}}{c^{k}}$.

Expected revenue in the first-price auction $R_{F P A}(N)=\frac{N-1}{N+1}=R(C, N)+\phi(C, N)$ (see the text). Thus, the percentage of possible revenues lost due to delay is

$$
\frac{\phi(C, N)}{R_{F P A}(N)}=\frac{1}{1+\chi} \frac{\sum_{k=2}^{N} \frac{1}{k}}{N-1}
$$

\section{References}

Ausubel, L., P. Cramton, and R. J. Deneckere (2002): "Bargaining with Incomplete Information," in Handbook of Game Theory, ed. by R. Aumann, and S. Hart, vol. 3, pp. 1897-1945. Amsterdam: Elsevier Science B.V. 
Bulow, J. (1982): "Durable Goods Monopolists," Journal of Political Economy, 90(2), $314-332$.

Bulow, J., And P. Klemperer (1996): "Auctions vs. Negotiations," American Economic Review, 86, 180-194.

Burrough, B., and J. Helyar (1990): Barbarians at the Gate: The Fall of RJR Nabisco. Harper \& Row Publishers.

Ellison, G., D. Fudenberg, And M. Mobius (2004): "Competing Auctions," Journal of the European Economic Association, 2, 30-66.

Klemperer, P. (2002): "What Really Matters in Auction Design," Journal of Economic Perspectives, 16(1), 169-189.

Levitt, S., And C. Syverson (2005): "Market Distortions when Agents are Better Informed: The Value of Information in Real Estate Transactions," NBER Working Paper Series, No. 11053.

McAfee, R. P., And D. Vincent (1997): "Sequentially Optimal Auctions," Games and Economic Behavior, 18, 246-276.

McLaughlin, R. (1990): "Investment Banking Contracts in Tender Offers: An Empirical Analysis," Journal of Financial Economics, 28, 209-232.

Skreta, V. (2004): "Sequentially Optimal Mechanisms," Working paper (UCLA).

Vartiainen, H. (2003): "Auction Design without Commitment," FEEM Working Paper No. 24 (Helsinki). 